\title{
国际城市设计专业教育模式浅析 基于多所知名高校城市设计专业教育的比较
}

\author{
Professional Education Programs in Urban Design: A Comparison Among Multiple Internationally \\ Renowned Universities
}

叶宇 庄宇

Ye Yu, Zhuang $Y u$

\begin{abstract}
摘要: 简要回顾当前国内城市设计专业教育的 发展情况和新常态下的发展机遇, 基于多所国 际知名高校的城市设计专业教育的比较分析, 总结了城市设计专业教育的几种主要办学方 向、培养时间与课程架构, 并探讨当下国内城 市设计专业教育的可能定位与发展方向, 为国 内城市设计教育从相对零散的课程发展成为全 面的学位教育提供建议。
\end{abstract}

Abstract: Based on a brief review of current progress of urban design education in China and emerging opportunities under the New Norms, a comparison of urban design education among multiple internationally renowned universities is made to generalize representative programmes. The education direction, program organization and curriculum framework in various universities are summarized to insight the potential development of professional education of urban design in China.

关键词: 城市设计; 专业教育; 培养模式

Keywords: Urban Design; Professional Education; Training Model

作者: 叶宇, 博士, 同济大学建筑与城市规划 学院建筑系助理教授。yye@tongji.edu.cn 庄宇, 博士, 同济大学建筑与城市规划 学院建筑系, 教授、博导; 同济大学建 筑设计院空间环境中心主任
城市设计作为对城市空间的设计和营造, 其本质是综合建成环境领域内的 城市规划、建筑学、景观建筑学等多个学科解决城市建设与更新过程中的一系 列问题, 进而提升城市空间环境, 实现更好的城市生活质量 ${ }^{[1,2]}$ 。随着我国经济 发展模式从高速迅猛的粗放增长向更精细化的“新常态”发展转变, 发展的质 量, 而非数量, 日益受到重视。城市空间品质及城市风貌因而也受到前所未有 的关注 ${ }^{[3]}$ 。

伴随着城市发展从“解决有无” 到 “提升品质” 的转型, 城市设计的重要性 也必将日益凸显。这一趋势需要更多的城市设计人才, 从而也需要城市设计专业 教育更加全面与正式。当下国内的城市设计专业教育如何应对新常态下新的发展 趋势, 如何从国际知名高校城市设计专业办学模式中汲取经验, 仍是一个亟须探 讨的话题。

\section{1 当前国内城市设计教育的发展概况 : 成就与机遇}

我国城市设计教育始于 20 世纪 80 年代 ${ }^{[4]}$ 。当时一些高校相继翻译引进了城 市设计的经典理论, 并开展了相关研究, 城市设计方向的课程和设置亦以此为起 点逐步展开。到 20 世纪 90 年代, 城市设计教育的重要性得到了更广泛的认知。 许多高校将城市设计理论与实践课程纳人建筑学和城市规划本科及硕士的教学计 划, 城市设计被普遍认可为一个研究方向, 相应的学会与学术组织机构相继成立, 多套城市设计教材陆续出版 ${ }^{[5]}$ 。

然而由于城市设计本身的综合性和复杂性, 国内对城市设计教育缺乏统一认 识, 多将城市设计作为一个研究方向而非独立的专业学科。学科归属争论不休, 城市设计不论在建筑学还是城市规划学科中都处于相对边缘的位置, 教育与研究 一直缺乏系统性 ${ }^{[6]}$, 这一情况导致国内的城市设计教育与境外诸多高校多年来的 教育实践存在距离。近年来随着城市设计重要性的进一步提升, 是否筹建以及如 何筹建具有学位授予权的城市设计专业的探讨正在逐步展开。

这一情况引发了亟须回答的一系列问题 : 在当下如何组织我国城市设计专 业的构建? 其形式如何? 培养时间、方向与学制如何划定? 城市设计教育中有 哪些需要涵盖的关键内容? 国际城市设计教育界对于这些问题的相关理论探讨 已被整理出来 ${ }^{[7]}$, 但关于城市设计教育实践仍欠缺清晰的总结。本文试图比较分 析多所国际知名高校的城市设计专业, 总结国际城市设计专业教育的几种主要办 
学方向、培养模式与课程架构, 并基于此探讨当下国内城 市设计专业教育的可能定位与发展方向。

\section{2 国际知名高校城市设计专业的初步比较}

\section{1 样本选取}

本研究依据日前发布的《QS 世界大学排名 : 建筑及建 成环境》 ${ }^{[8]}$ 中位列前 20 的知名高校作为基础样本, 去除未 开设城市设计专业的高校和我国内地高校, 最终选取 13 所 国际高校的 15 个城市设计专业项目作为研究对象, 并逐一 记录各个专业的办学主导院系、学位类型、培养时间、培养 方向及学制等（表 1 )。这 15 个城市设计专业的选取也考虑 了各个学术体系的代表性。15 个专业所属地区（体系）分
布如下: 北美（美国及加拿大） 6 个, 如麻省理工学院、加 州大学伯克利分校、英属哥伦比亚大学等; 英式体系（英国 及澳大利亚） 5 个, 如伦敦大学学院、剑桥大学等; 欧洲大 陆 2 个, 即代尔夫特理工大学和苏黎世理工大学; 亚洲 2 个, 即新加坡国立大学和香港大学 (图 1A)。

\section{2 办学背景}

在 15 个样本中, 有 7 个为建筑学办学背景, 4 个为城市规 划办学背景 (图 1B), 可见当前国内城市设计以建筑学和城市规 划为学科主线的方针与境外高校的办学思路基本是一致的。建筑、 城市规划、景观建筑学等多学科高度融合是城市设计专业的常见 情况 (3 个), 基于景观建筑学的城市设计项目亦能见到（1个）。

表 1 QS 世界大学排名（建筑及建成环境前 20 名）中开设有城市设计专业或证书的知名高校（2015 年）

\begin{tabular}{|c|c|c|c|c|c|c|c|}
\hline 排名 & 国家（地区） & 学校名称 & 城市设计项目名称 & 办学背景 & 学位类型 & 培养时间 & 学制 \\
\hline 1 & 美国 & 麻省理工学院 & $\begin{array}{l}\text { 城市设计证书 } \\
\text { Urban Design Certificate for Master Students }\end{array}$ & 建筑＋规划 & 证书 & 非完整项目 & 全 \\
\hline \multirow[t]{2}{*}{2} & \multirow[t]{2}{*}{ 英国 } & \multirow[t]{2}{*}{ 伦敦大学学院 } & $\begin{array}{l}\text { 建筑学硕士（城市设计） } \\
\text { Master of Architecture in Urban Design }\end{array}$ & 建筑 & “后”职业学位 & 一年 & 全/非 \\
\hline & & & $\begin{array}{l}\text { 理学硕士（城市设计与规划） } \\
\text { Master of Science in Urban Design and City Planning }\end{array}$ & 规划 & “后” 职业学位 & 一年 & 全/非 \\
\hline 3 & 荷兰 & 代尔夫特理工大学 & $\begin{array}{l}\text { 理学硕士（城市学） } \\
\text { Master of Science in Urbanism }\end{array}$ & 规划 & 职业学位 & 二年 & 全 \\
\hline 4 & 美国 & 加州大学伯克利分校 & $\begin{array}{l}\text { 城市设计硕士 } \\
\text { Master of Urban Design }\end{array}$ & 建筑 & “后” 职业学位 & 一年 & 全 \\
\hline \multirow[t]{2}{*}{5} & \multirow[t]{2}{*}{ 美国 } & \multirow[t]{2}{*}{ 哈佛大学 } & $\begin{array}{l}\text { 建筑学硕士（城市设计） } \\
\text { Master of Architecture in Urban Design }\end{array}$ & 建筑 & “后” 职业学位 & 二年 & 全 \\
\hline & & & $\begin{array}{l}\text { 景观建筑学硕士（城市设计） } \\
\text { Master of Landscape Architecture in Urban Design }\end{array}$ & 景观 & “后” 职业学位 & 二年 & 全 \\
\hline 6 & 新加坡 & 新加坡国立大学 & $\begin{array}{l}\text { 文学硕士（城市设计） } \\
\text { Master of Arts in Urban Design }\end{array}$ & 建筑 & “后” 职业学位 & 一年 & 全/非 \\
\hline 7 & 瑞士 & 苏黎世理工大学 & $\begin{array}{l}\text { 高级研究硕士（城市设计） } \\
\text { Master of Advanced Studies in Urban Design }\end{array}$ & 建筑 & “后” 职业学位 & 一年 & 全 \\
\hline 9 & 英国 & 剑桥大学 & $\begin{array}{l}\text { 哲学硕士（建筑与城市设计） } \\
\text { Master of Philosophy in Architecture and Urban Design }\end{array}$ & 建筑 & “后” 职业学位 & 二年 & 全 \\
\hline 11 & 美国 & 哥伦比亚大学 & $\begin{array}{l}\text { 理学硕士（建筑与城市设计） } \\
\text { Master of Science in Architecture and Urban Design }\end{array}$ & 建筑 & “后” 职业学位 & 一年 & 全 \\
\hline 13 & 香港 & 香港大学 & $\begin{array}{l}\text { 城市设计硕士 } \\
\text { Master of Urban Design }\end{array}$ & 规划 & “后” 职业学位 & 一年 & 全 \\
\hline 15 & 澳大利亚 & 墨尔本大学 & $\begin{array}{l}\text { 城市设计硕士 } \\
\text { Master of Urban Design }\end{array}$ & 建筑＋规划 & 职业学位 & 二年 & 全/非 \\
\hline 17 & 澳大利亚 & 悉尼大学 & $\begin{array}{l}\text { 城市设计（证书、文凭、硕士） } \\
\text { (Certificate, Diploma and Master) of Urban Design }\end{array}$ & 规划 & $\begin{array}{l}\text { 从证书到“后” } \\
\text { 职业学位 }\end{array}$ & $\begin{array}{l}\text { 半年到一年 } \\
\text { 半 }\end{array}$ & 全/非 \\
\hline 20 & 加拿大 & 英属哥伦比亚大学 & $\begin{array}{l}\text { 城市设计硕士 } \\
\text { Master of Urban Design }\end{array}$ & 建筑＋景观 & “后” 职业学位 & 一年 & 全/非 \\
\hline
\end{tabular}

注：（1）表格中“全”指“全日制”，“全/非”指“全日制与非全日制皆有”; (2) 位列前 20 的日本东京大学和韩国首尔国立大学虽然有城市设 计的研究团队, 但由于不颁发相应的学位或证书, 难以称为一个完整的专业, 故未列入。 


\section{3 学位类型}

15 个样本中, 城市设计专业均为硕士阶段的教育, 未 见相应的本科专业教育。其中大多数（11 个）属于 “后” 职 业学位 (Post-professional Degree), 只有少量属于职业学位 ${ }^{1}$ (Professional Degree), 还有少量非学位类型的证书（图 1C)。 这里 “后” 职业学位是指学生通过本科及硕士教育取得相应 的建筑、城市规划或景观方向的职业学位后, 想继续在某个 方向深造而进一步选择的学位。职业学位是指从零基础培养 相应专业设计师的学位课程, 其伴随着职业注册制度出现, 完成一个职业学位是取得职业注册的先决条件。

由此可见, 城市设计专业教育在当前国际语境中大多被 认为是完成建筑、城市规划或景观建筑学职业教育之后的进 一步拓展。但样本中也有像墨尔本大学和代尔夫特理工大学 这样, 将城市设计专业作为职业学位, 直接将其构建在本科 教育之上的案例。此外, 城市设计专业教育由于其内容庞杂, 可拓展性强, 也有学校采取城市设计证书的形式, 选修完成 相应课程即可颁发。例如悉尼大学依据选修课时的多少, 可 以分别颁发城市设计硕士 (Master of Urban Design) 、城市设 计文凭 (Diploma) 或城市设计学习证书 (Certificate) 等不 同的学位证书, 实现了城市设计专业教育的弹性化。具体来 说, 修读完整个城市设计培养体系的相应课程则颁发硕士学
位 ; 修读完指定主干课程则颁发城市设计文凭 ; 仅修读部分 相关课程则颁发学习证书。

\section{4 培养时间及学制}

在选取的样本中, 城市设计专业多为一年制 (8 个), 也 有少部分为两年制 (4 个), 以及时间可变的弹性培养模式。 由于城市设计专业本身具有较强的 “后” 职业教育色彩, 相 当数量的学校 (6 个) 也有为已经工作的专业人员提供非全 日制教育的教学方案 (图 $1 \mathrm{D}, \mathrm{E})$ 。

\section{3 城市设计专业课程架构与内容的样本分析}

\section{1 课程架构}

具体而言, 这些知名高校中的城市设计课程架构依据培 养方式的不同, 可以分为设计导向和设计与研究相结合的培 养模式。其中设计导向是绝对的主流, 但亦存在强调设计实 践与设计研究相结合的案例。具体而言, 设计导向下的城市 设计专业架构可以细分为如下三种 (表 2)。

首先是以哥伦比亚大学等为代表的 “设计工作坊主导” 模式 (表 3)。整个授课, 包括城市形态与历史理论讲座与 设计实践在内的全过程, 都以设计工作坊为基础展开。哥伦 比亚大学城市设计的一年制项目共分为三个小学期, 每个学

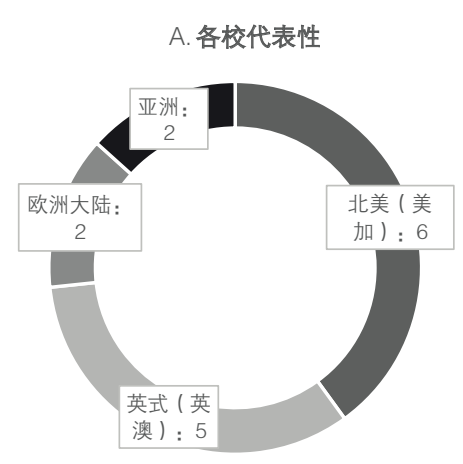

D. 培养时间

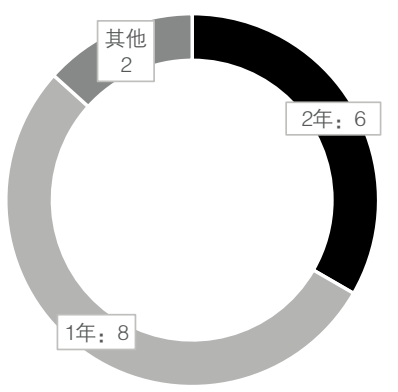

B. 办学背景

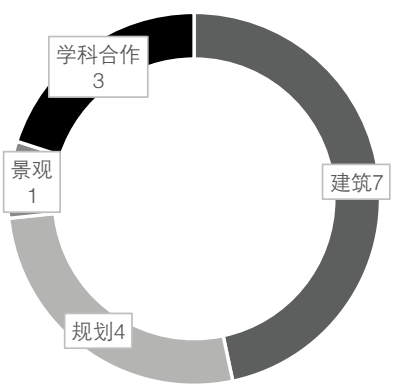

E. 学制

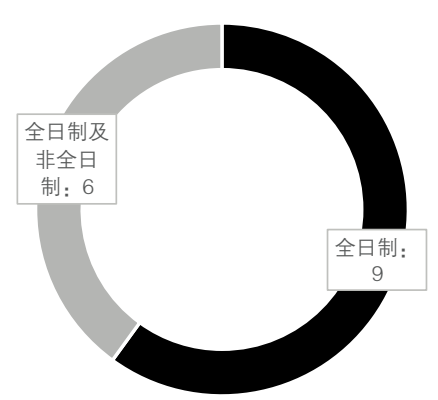

C.学位类型

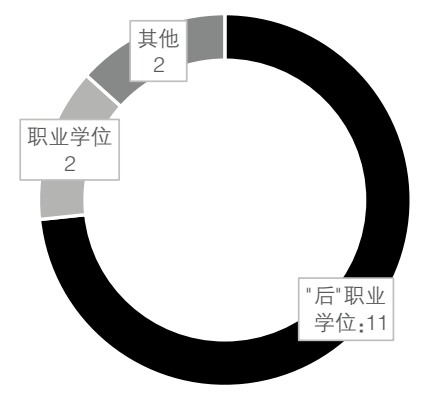

图 1 所选城市设计专业各项基本情况分析

(1) 以英美欧为代表的高等教育体系中, 本科阶段为通识基础教育 (3 4 年), 硕士阶段 (1 2 年) 为职业教育。我国建筑、规划及景观专业的五 年制本科在教学目的上为职业教育, 在教学时间上近似于国外高校本科与硕士教育的结合。 
期以一个主题的设计工作坊为主导, 辅以与设计工作坊主题 相对应的城市设计研讨会等理论课程和少量开放选修课。这 种模式高度强调设计能力的培养, 多见于以建筑学为办学基 础的学校。

其次是以加州大学伯克利分校等为代表的 “理论课程 + 设计工作坊 + 小论文” 模式, 以包括设计工作坊及相关设计 理论在内的核心系列课程为基础, 加上额外的设计工作坊、 方法论、城市历史与理论等宽口径课程辅助, 最后以设计导 向的小论文结束 (表 4)。这种模式更强调城市设计的复杂 性与过程性, 在单纯的空间设计之外更多地引入政策、经济、
社会等学科, 力求在短短的一年内形成较为完备而全面的理 论与实践技能培养。

此外还有以哈佛大学建筑学硕士（城市设计）和景观建 筑学硕士 (城市设计) 为代表的模式。建筑学与景观建筑学 专业共享一个相同的城市设计核心系列课程, 随后依照学生 兴趣各自朝建筑学和景观建筑学两个方向拓展 (表 5)。具 体而言, 在第一学年学生主要完成通用的城市设计核心课 程（占 $35 \%$ 学时）, 随后则专注于各自本来的专业方向（占 $65 \%$ 学时)。通过两年的培养, 保证学生在具有建筑学或景 观建筑学专业技能的同时, 兼具城市设计方面的能力。

\section{表 2 城市设计专业典型课程构架分析}

\begin{tabular}{|c|c|c|c|}
\hline 培养方向 & 课程架构 & 代表项目 & 特点 \\
\hline \multirow[t]{3}{*}{ 设计导向 } & 工作坊主导 : 理论系列讲座 + 设计实践 & \begin{tabular}{|l|} 
伦敦大学学院建筑学硕士 (城市设计)、 \\
哥伦比亚大学等
\end{tabular} & 一年制, 以建筑学为基础 \\
\hline & 理论课程＋设计工作坊＋小论文 & $\begin{array}{l}\text { 加州大学伯克利分校、伦敦大学学院理 } \\
\text { 学硕士（城市设计与规划）等 }\end{array}$ & 一年制, 以城市规划为基础 \\
\hline & $\begin{array}{l}\text { 城市设计核心系列课程（理论讲座＋设计工作坊）+建筑或景观 } \\
\text { 的发展方向深化（课程＋设计工作坊＋选修课或小论文） }\end{array}$ & $\begin{array}{l}\text { 哈佛大学 : 建筑学硕士（城市设计）、景 } \\
\text { 观建筑学硕士（城市设计） }\end{array}$ & $\begin{array}{l}\text { 两年制, 城市设计作为建筑及景观 } \\
\text { 学科的外延 }\end{array}$ \\
\hline $\begin{array}{l}\text { 设计与研究相 } \\
\text { 结合 }\end{array}$ & 理论课程 + 设计工作坊 + 大设计论文 & 代尔夫特理工大学、剑桥大学 & $\begin{array}{l}\text { 两年制 (一年设计 }+ \text { 一年研究), 强 } \\
\text { 调基于研究的设计 }\end{array}$ \\
\hline
\end{tabular}

\section{表 3 哥伦比亚大学的城市设计专业课程架构}

\begin{tabular}{l|l|l|l}
\hline \multirow{2}{*}{ 课程类别 } & \multicolumn{1}{|c}{ 课程名称 } \\
\cline { 2 - 4 } & \multicolumn{1}{|c|}{ 第一学期 / 年 } & \multicolumn{1}{c}{ 第二学期 / 年 } & 第三学期 / 年 \\
\hline 城市设计核心课程 & 城市设计工作坊 I (9 学分) & 城市设计工作坊 II (9 学分) & 城市设计工作坊 III (9 学分) (1) \\
\hline $\begin{array}{l}\text { 城市设计工作坊的 } \\
\text { 辅助课程 }\end{array}$ & $\begin{array}{l}\text { 讲座系列 I: 后工业时代的城市理论与设计 (3 } \\
\text { 学分) }\end{array}$ & 讲座系列 II : 城市肌理与类型学 (3 学分) & 讲座系列 III : 基础设施、弹性与公共空间 (3 \\
\cline { 2 - 5 } & 解读纽约城市 (3 学分) & 开放式选修 (3 学分) & 学分) \\
\hline
\end{tabular}

\section{表 4 加州大学伯克利分校的城市设计专业课程架构}

\begin{tabular}{|c|c|}
\hline 课程类别 & 课程名称 \\
\hline 城市设计核心课程（必修） & 城市场所（高级工作坊, 5 学分）; 城市场所（研讨会, 3 学分）; 城市场所 (经济模块, 1 学分); 城市场所研究 (1 学分) \\
\hline 第二设计工作坊（选修一门） & $\begin{array}{l}\text { 基于城市设计视角的建筑设计案例研究 (5 学分) ; 高级城市设计工作坊（5 学分）; 景观场所设计（5 学分）; 高级项目设计 (5 } \\
\text { 学分) ; 基于城市设计视角的环境规划工作坊 (5 学分) }\end{array}$ \\
\hline 方法论（选修一门） & 环境设计中的研究方法（4 学分）; 规划过程中的公众参与（3 学分）; 基于城市设计视角的建筑设计研讨会（3 学分） \\
\hline 城市历史与理论（选修一门） & 城市形态历史及理论（3 学分）; 发展中国家的城市设计与住房（3 学分）; 景观建筑学与环境规划理论（2 学分） \\
\hline 小论文 (必修) & 论文工作坊（4 学分） \\
\hline
\end{tabular}

表 5 哈佛大学的城市设计专业课程架构

\begin{tabular}{ll}
\hline 课程类别 & \multicolumn{1}{c}{ 课程名称 } \\
\hline 通用城市设计核心课程 & 城市设计要素 (核心工作坊, 8 学分); 城市与设计 I (4 学分); 城市与设计 II (4 学分); 定义城市设计 (研讨会, 4 学分); \\
& 城市规划与设计工作坊 (8 学分) \\
建筑学和景观建筑学的培养路径 & 各种课程选修或论文 (共 52 学分) \\
\hline
\end{tabular}

(1) 因为不同学校的学分所对应的学时不一,所以表 3-表 6 中的学分多少仅能反映各自学校的教学偏重, 无法在不同学校之间横向比较。 
不同于以上以设计为导向的教学模式, 以代尔夫特理工 大学、剑桥大学等为代表的设计实践与设计研究相结合的模 式希望通过两年教育来保证学生实践能力和研究思辨能力的 双向培养。以代尔夫特理工大学的理学硕士 (职业学位) 为 例, 在课程架构上先通过一整年的宽口径设计理论与设计工 作坊来保证学生的基本城市设计能力, 后一年则是以研究为 先导的设计论文, 要求基于研究完成毕业设计并提交大论文 (表 6)。

\section{2 课程内容分析}

对于诸多样本高校城市设计课程内容的分析有助于揭示 当前国际城市设计教育的关注点, 进而明确我国城市设计专 业课程的设置。通过对样本高校所有城市设计课程名称进行 学分加权之后的词频统计分析, 从高到低选取了当下国际城 市设计教育的 10 个关键词 (表 7)。

位列最前的关键词毫无疑问是 “城市设计/城市设计 工作坊”。正如美国学者特兰西克 (Trancik) 所指出的, 城 市设计的核心即是通过设计来进行城市空间营造 ${ }^{[9]}$, 因此 对于设计能力的培训是所有城市设计课程体系的核心。这 一点与之前表 3-表 6 的结果相吻合, 不同导向、不同背 景的城市设计课程体系均包含设计工作坊这一项并赋子了 大量学时。

“城市规划” 和 “建筑学” 分别位列第二和第七位, 充 分展现了这两个学科作为城市设计主线内容的地位。值得指 出的是, 相当数量属于建筑学内容的设计课程被归纳到 “城 市设计/城市设计工作坊” 这一类中, 所以不能简单以词频 高低作为学科重要程度的代表。“可持续” 位列第三, 反映了 当下城市设计教育中对于可持续发展与环境要素的关注 ${ }^{[10,11]}$ 。 “城市形态” 与 “城市历史” 等理论讲座作为城市设计的基 础理论要素, 在城市设计专业教育课程中也高频出现, 分别 位列第四和第五位。这反映了城市设计学科本身根植于城市 形态之上, 基于对于过往城市历史与形态演变的把握来寻求 更美好的城市空间环境设计的诉求。此外 “场所/场所营造” 体现了学界近年来对城市场所质量的关注, 也被视为当前城 市设计课程中的重点, 位列第八。

\section{表 6 代尔夫特理工大学的城市设计专业课程架构}

\begin{tabular}{|c|c|}
\hline 课程类别 & 课程名称 \\
\hline $\begin{array}{l}\text { 城市设计与规划工 } \\
\text { 作坊（第一年） }\end{array}$ & $\begin{array}{l}\text { 工作坊 I : 城市形态的分析与设计 (15 学分); 工作坊 } \\
\mathrm{II} \text { : 城市的社会空间过程及介人 (15 学分); 工作坊 III : } \\
\text { 全球城市的规划与设计策略 (15 学分); 工作坊 IV : 开 } \\
\text { 放选修 (15 学分) }\end{array}$ \\
\hline $\begin{array}{l}\text { 以研究为先导的设 } \\
\text { 计论文 (第二年) }\end{array}$ & $\begin{array}{l}\text { 研究选题、方法论及相关理论 (10 学分) ; 论文计划及 } \\
\text { 深人 (15 学分) ; 完成大设计及论文 (30 学分) }\end{array}$ \\
\hline
\end{tabular}

值得一提的是, “研究 / 研究方法 / 方法论”也在当前 城市设计专业课程中频繁出现, 反映了城市设计中 “研究先 导” 这一观点正逐步被广泛采纳。此外位列第九和第十的 “策 略 / 政策 / 控制” 及 “过程 / 参与 / 协商”也值得重视。城市 设计实践正在经历从基于直觉的形态设计向系统化的城市设 计策略与过程转向, 城市设计的社会性和政策性进一步得到 重视 ${ }^{[12,13]}$ 。这一趋势很明显地反映在了相应的课程教育上。

如上可见, 城市设计课程内容所体现的专业定位介于城 市规划与建筑学之间, 其核心由城市规划学科对物质空间形 态及其对于社会经济影响的关注和建筑学科对户外空间设计 艺术的考量所共同构筑; 在这一基础之上, 再向设计实施、 环境因素、历史演变等方向拓展和交织形成的多学科多侧重 的复杂体系。不同的办学背景、学位类型、培养时间等都会 催生略有不同但核心类似的城市设计专业教育模式, 但其中 保持不变的是规划与建筑相结合这一特点。不论是以建筑学 还是城市规划作为办学基础, 都必须打破学科藩篦, 吸收多 元学科教师来组织教学工作, 构建全面的课程体系, 这一点 对于我国未来的城市设计教育发展具有重要启示作用。

\section{4 总结与启示}

\section{1 城市设计专业教育的学科背景}

回顾以上诸多样本, 国际城市设计教育在其背景定位上 一般以建筑学和城市规划为基础, 呈拓展的趋势, 日益强调 宽口径的学科整合、理性的设计研究和综合的经济社会考量。 因此, 当下我国城市设计专业教育的办学可以考虑依托现有 的建筑学和城市规划团队构建各有侧重的建筑学（城市设 计)、城市规划（城市设计）等学位, 进一步拓展各个专业 对于城市设计的了解和掌握。但在这一过程中需要打破学科 界限, 构筑多学科的教学团队和课程, 避免建筑学 (城市设

\section{表 7 城市设计专业课程名称的词频分析}

\begin{tabular}{|c|c|}
\hline 词频排名 & 关键词 \\
\hline 1 & $\begin{array}{l}\text { 城市设计/城市设计工作坊（urban design/urban design studio/ } \\
\text { design） }\end{array}$ \\
\hline 2 & 规划 / 城市规划（planning/urban[city] planning） \\
\hline 3 & 可持续（sustainable/sustainability） \\
\hline 4 & 城市形态 / 城市形态学 (urban form/morphology) \\
\hline 5 & 历史 / 城市历史 / 城市理论（history/urban history/urban theory） \\
\hline 6 & $\begin{array}{l}\text { 研究 / 研究方法 / 方法论 (research/research methods } \\
\text { methodology) }\end{array}$ \\
\hline 7 & 建筑学 (architecture) \\
\hline 8 & 场所 / 场所营造（places/place-making） \\
\hline 9 & 策略 / 政策 / 控制（strategy/policy/control） \\
\hline 10 & 过程 / 参与 / 协商 (process/participation/negotiation) \\
\hline
\end{tabular}


计）只关注中小尺度的户外空间，城市规划（城市设计）只 关注大尺度整体城市设计等情况出现。如果条件合适, 直接 建立整合多学科特点的宽口径、厚基础、全面综合的城市设 计专业学位则更好。

\section{2 城市设计专业教育的定位}

国际城市设计教育以 “后”职业学位为主流，亦有少数 职业学位, 但都需要学生先完成相关学科的基础学习。因此, 当下我国城市设计专业的学位建设应考虑以硕士教育为主, 要求学生先完成建筑学、城市规划或景观建筑学学专业的本 科学习。可以考虑以当前的专业硕士和科学硕士分别对应国 际上的设计导向和设计与研究相结合导向的两类城市设计专 业教育。专业硕士应以设计工作坊为核心, 配合相应的理论 课程、讲座和论文。科学硕士则应更注重城市设计过程中的 分析、研究和经济社会外延, 为未来的博士研究奠定基础。 不过考虑到我国的五年制本科教育本身具有较强的职业教育 属性，不同于国外三至四年的基础教育，亦可考虑在本科阶 段引人一年的城市设计专业教育, 形成 “ $4+1$ ” 模式。在保 证学生具有基本专业技能、主干理论知识的基础上, 进行方 向差异性培养。

\section{3 城市设计专业教育的教学与学制}

国际城市设计教育当前多以设计工作坊为核心，辅以理 论课程和论文研究, 强调启发式、讨论式的教学, 同时也比 较注重对于城市空间形态背后的政策、经济和社会属性的探 讨。因而我们在教学内容和教学方法上, 一方面要坚持以城 市空间形态为核心的城市设计工作坊、城市形态、城市历史、 场所营造等物质空间方面的内容; 另一方面也要注意城市设 计学科的复杂性, 注重城市设计的策略、协商以及城市设计 过程的教学, 以实现物质形态设计能力和对复杂城市问题的 思辨研究能力并举。与此同时, 在教学上应注重从空间形态 技能培训向设计研究能力拓展, 从设计方法教学向城市设计 策略拓展, 在教学方法上从灌输式教学向讨论型、研究型教 学拓展。当前国际城市设计教育中单纯以设计为导向的项目 学制多为一年; 强调研究与设计相结合或将城市设计作为建 筑学与景观建筑学专业教育延伸的项目, 其学制则多为两年。 此外, 城市设计本身作为一个多样化、复合化的领域, 学制 亦可保有足够的弹性 : 根据所修课时不同，分别颁发短期证 书或学位。我们可立足国内实际情况，对此加以探讨和考虑。

总而言之, 在过去的 30 多年中, 从翻译引进国外城市 设计理论到探索本土化的城市设计思想理论, 从少数特大城 市的城市设计国际竞赛到城市设计实践遍布全国，我国的城 市设计理论和实践有了长足发展。与实践的大幅进展相比,
当前的城市设计专业教育发展尚显迟缓。伴随着 21 世纪中 国快速城市化进程以及对于城市空间品质要求的迅速提升, 城市设计专业人才的缺口日益增大, 我国城市设计专业教育 必将迎来一个新的发展阶段。在这个过程中, 如何提升专业 教育水平, 实现学科教育的国际对接, 既要积极比照国际知 名高校的办学特色, 也要立足国内学科体系与自身特点, 科 学辩证地推动学科构建。ⓅI

注: 文中未注明来源的图表均为作者绘制。

\section{参考文献}

[1] Carmona M. Public Places, Urban Spaces: The Dimensions of Urban Design[M]. Routledge, 2010.

[2] 金广君.美国的城市设计教育 [J]. 世界建筑, 1991(5): 71-74.

[3] 石楠. 新常态下城市空间品质问题的新视角 [J]. 上海城市规划, 2015(1): 1-3.

[4] 王建国. 21 世纪初中国城市设计发展前瞻 [J]. 建筑师, 2003(1): 19-25.

[5] 何峰, 周国华.《城市设计》教材比较研究 [J]. 高等建筑教育, 2009, 18(6): 66-70.

[6] 孙一民. 近期美国麻省理工学院的城市设计教育 [J]. 建筑学报, 1999(5): 50-52.

[7] Pittas M, Ferebee A. Education for Urban Design: A Selection of Papers Presented at the Urban Design Educators' Retreat[C]. Institution for Urban Design, San Juan, Puerto Rico, 1982.

[8] Top Universities. QS World University Rankings by Subject 2015 Architecture / Built Environment[EB/OL]. (2015-09-15)[2015-10-18]. http://www.topuniversities.com/university-rankings/university-subjectrankings $/ 2015 /$ architecture\#sorting $=$ rank + region $=+$ country $=+$ faculty $=+$ star $\mathrm{s}=$ false + search $=$.

[9] Trancik R. Finding Lost Space: Theories of Urban Design[M]. John Wiley \& Sons, 1986.

[10] Cook R S. Zoning for Downtown Urban Design: How Cities Control Development[M]. Lexington Books, 1980.

[11] Bentley I. Urban Design Part 3: Ecological Urban Design[J]. Architects' Journal, 1990, 192: 69-71.

[12] Madanipour A. Design of Urban Space: An Inquiry into a Socio-Spatial Process[M]. Chichester: Wiley, 1996.

[13] Lang J T. Urban Design: A Typology of Procedures and Products[M]. Routledge, 2005 